\title{
User-centered Design for Mobile Apps Guide Service Heritage Tourism in Indonesia
}

\author{
https://doi.org/10.3991/ijim.v14i16.11312 \\ Erni Widarti, Dadang Eman, Suyoto ${ }^{(凶)}$ \\ Universitas Atma Jaya Yogyakarta, Yogyakarta, Indonesia \\ suyoto@uajy.ac.id
}

\begin{abstract}
Heritage tourism is a tour by visiting places that have historical value and heritage value as a tourist attraction. Indonesia is one of the countries that have heritage tourism. The purpose of this study is to propose the design of mobile applications for heritage tourism in Indonesia. In this study, three places were selected in Indonesia, namely Yogyakarta, Bandung, and Bali. Tourism phone application design is a tour guide application service that encourages tourists to get information about cultural heritage travel. With this application, users choose tour packages according to the area they want to visit. The method used in this research is to use the user-centered sign (UCD) method. UCD is a recurring design process where designers focus on users and their needs in each phase of the design process. This application makes it easy for tourists because it is a tool for authentic travel. Tourists can access the route, and tourist destinations will be discussed during the Inheritance trip. The results of the design of tour guide services with $77 \%$ that indicate this study was successful. Based on the application design proposed in designing tour guide services by user expectations.
\end{abstract}

Keywords - Heritage Tourism, User-Centered Design, Mobile Guide Service.

\section{$1 \quad$ Introduction}

Heritage tourism is a tourist trip to find out places and cultures that exist in an area that has historical value and is inherited from ancestors (Asmelash and Kumar, 2019). The Indonesian nation is a nation that has diverse local cultural heritage values. With the existence of heritage tourism can preserve the cultural history that exists in Indonesia and introduces it from generation to generation. The number of foreign tourist arrivals or international tourists to Indonesia in June 2018 rose 15.21 per cent compared to the number of visits in June 2017, namely from 1.14 million visits to 1.32 million visits. Similarly, when compared to May 2018, the number of foreign tourist visits in June 2018 increased by 6.07 per cent (Statistik, 2018).

Heritage tourism development is used to preserve and promote economic growth through cultural and historical tourism approaches (Jeon et al., 2016). Cultured life has an essential role in protecting the cultural values of society; the power of attraction to a culture in tourism is a pride, as well as the identity of a community (Jeon et al., 2016). Efforts to preserve cultural heritage are not only carried out in Indonesia but also in all 
countries in the world. Heritage Education in the Al Hassa Region, Saudi Arabia's social studies curriculum at K-12 analyses the impact of the Interactive Virtual Museum as a method for learning about effective ways to increase awareness and knowledge of national heritage (Ismaeel and Al-Abdullatif, 2016).

However, most of the tourists who come to visit heritage sites are less able to understand what history and culture are in these tourist attractions because not all of these tourist attractions provide free tour guide facilities so that tourists have to pay extra fees to explain this - historical and cultural information on these tourist attractions (McGookin et al., 2019).

With the development of technologies such as electronic guidance systems for tourism can be used to help tourists access tourism information directly from their smart devices, anytime and anywhere becomes easier (Dirin et al., 2018). One of them is the mobile application, which can be used to assist in providing historical information about heritage tourism. Tourists can access data directly via smartphone easily and quickly without having to have a tour guide who explains information on cultural history in heritage tourist attractions (Chiao et al., 2018). Indonesia has many tourist attractions, especially cultural tourism, including in Papua, East Nusa Tenggara, West Nusa Tenggara (Lombok), Bali, East Java (Malang), Special Region of Yogyakarta, Central Java (Sragen), West Java (Bandung), North Sumatra(Aceh),South Sumatra (Lampung), South Sulawesi (Toraja).

Three tourist attractions in Mobile Apps Guide Service Heritage Tourism in Indonesia are famous for their heritage tourism, a mobile guide service application is used to providing information and knowledge about history, culture, and inheritance in Indonesia. The approach used in this study is the approach of the user center design. The user-centered design is a design that places the user as the center of a system development process. With a Mobile guide tourism application that uses the UCD method, it is expected that tourism users or users can have insight or knowledge and introduce cultural heritage in Indonesia.

\section{Literature Review}

The tourism industry is one sector that is always increasing every year. One study conducted by Neidhardt and Werthner, namely heritage tourism, in this study, tourist attractions that have cultural, a historical value in an area or city as a tourist attraction. With the internet, tourism places can be easily published through websites, social media, youtube, and blogs, so tourists want to visit the tourism place (Neidhardt and Werthner, 2018).

Research conducted by Gulbahar and Yildirim, Tourism is one of the important economic sectors in an area. The research was conducted in Turkey, Turkey, which described the use of social media and mobile applications aimed at marketing tourism for tourism companies. (Gulbahar and Yildirim, 2015). The technology that is developing at this time facilitates in making mobile-based applications. Various mobile apps that have been developed, aiming to promote users to get easy access to information (Dickinson et al., 2018). Based on research from Chitralada (Suphachaimongkol et al., 
2019), introduces and develops the mobile application process for sustainable creative tourism (SCT) using the confirmatory factor analysis (CFA) approach. The process in the study was divided into 4 phases which showed that the study fulfilled the requirements to establish indicators for the assessment of the new SCT.

According to Gretzel et al., provide information on the cultural history of ancestors that are available in these tourist sites, several research studies have developed a smart tourism industry to increase tourist attraction. Smart tourism in question is discussing the current smart tourism trends and explaining the general picture that underlies the concept of smart tourism, the basis of technology and business generated from these smart tourism (Gretzel et al., 2015).

Cultural tourism development strategies can be developed with several approaches, including a game-based approach (Aguilar et al., 2015)(Xu et al., 2017). Using these various approaches has the same goal, namely to increase the attractiveness of tourists to visit the tourist attractions. Another technique often used in heritage tourism research studies is Augmented Reality (AR). AR is increasingly being used in research studies to be used in heritage tourism destinations to enhance experience and knowledge in travel that is focusing on the aesthetics and characteristics of AR (Vainstein et al., 2016)(Jung et al., 2018).

The tourism sector uses a user-centered design that is targeted at developing cellular services for outdoor activities such as hiking, biking and so on so that the presence of a mobile-based system supports tourism activities (Alamäki and Dirin, 2014). A summary of each of the previous studies on tourism includes Rui Su; this study interprets heritage tourism in an urban context using the CPE (cultural, political economy) approach case study of heritage tourism in Nanjing, China. The result of urban heritage tourism involves agency structures and economic, cultural relations. In this paper, using CPE approaches focuses on bringing together agents and structural processes involved in heritage tourism in urban contexts (Su et al., 2018).

In promoting tourism, Constantinou, researched cultural heritage and information dissemination using interactive small screen technology. The research especially for deaf visitors to provide experience while visiting the museum without the support of physical sign interpreters, in this study showed a high level of user satisfaction and the utility of the application in allowing deaf museum visitors to take a fun tour, using their mobile devices as the only means of support. This application was tested at the Pattichion City Museum in Cyprus (Constantinou et al., 2016).

Explore the potential impact of cultural heritage by using social computing systems to increase people's access to cultural heritage, primarily focusing on deaf and disabled users. In this study concluded that the challenge for the application of social computing is inclusive in the context of cultural heritage and shows fields in which future research is needed (Kosmas et al., 2019).

The cultural heritage in Indonesia is one of the studies conducted by Marimin, a palace in Surakarta. Surakarta Palace Kasunanan is still not a popular tourist destination. The research is qualitative, to analyse and describe the images in the Surakarta palace as a tourist attraction (Marimin, 2016). In reviewing tourism using the forecasting method conducted by Hayan Song, in this study, the comparison of the performance methods of the forecasting model by reviewing 211 papers between 1968 and 2018. 
Considering the trends and evolution of forecasting methods demand tourism from a historical perspective in 4 categories of ways, namely time series, econometrics, AI models and assessment methods (Song et al., 2019).

The use of user-centered design methods in various fields such as in the areas of education (Hamdi and Hamtini, 2016), cartography, GIScience and visual analytic (Roth et al., 2015), games (Brox et al., 2017), hospitality (Esteves and Pereira, 2015), medical (Risald et al., 2018), etc. Research conducted by Esteves, et al., in the field of hospitality for mobile hospitality applications using user-centered design, applications designed to propose communication services between hotel staff and hotel guests, increase user satisfaction and reduce response time so that users are more efficient in spent time (Esteves and Pereira, 2015). Schnall, et al., to design health applications, the results of this study are to support the use of a framework of Information System Research as a guide for developing future health applications (mHealth) (Schnall et al., 2016). According to Muljono et al., in a previous study, stated that User-Centered Design (UCD) can be applied to design applications and can be used to analyse problems and conceptual models of user needs. The theoretical model in question is using images, lipreading videos, text, and sign language to make it easier for users to understand the content (Muljono et al., 2019).

In the field of tourism, explain the previous research related to tourism research with the results and improvements of each of these studies. While in this study, the focus is on the method used, namely the UCD method that has not been used in previous research in the field of tourism about application guide service tourism. The application design in this study will significantly help users by using the UCD concept.

\section{Purposed Method}

This study uses UCD on the mobile design guide to service heritage tourism. The flow diagram of the research method is, as shown in Figure 1.

Figure 1 is the flow of research that has several stages, among others, namely identification of user needs, designing design interfaces, then making prototypes of mobile applications consisting of creating a storyboard, prototype design, and prototype evaluation. The last step is the identification of reactions from users.

Data collection is done using literature studies and field studies. The literature study is the primary collection of theories related to this research in books, journals. Field studies include direct observation of tourists/visitors and conducting interviews with tourism. The data used in making guide service tourism applications comes from tourist attractions that can provide information to the end such as information on operating hours, ticket prices, other information such as dance performances or cultural customs at the tourist attractions. In this study, the proposed mockup at the beginning was obtained from the results of reading literature, interviews, and observations from tourist attractions so that mockups were proposed in this study. 


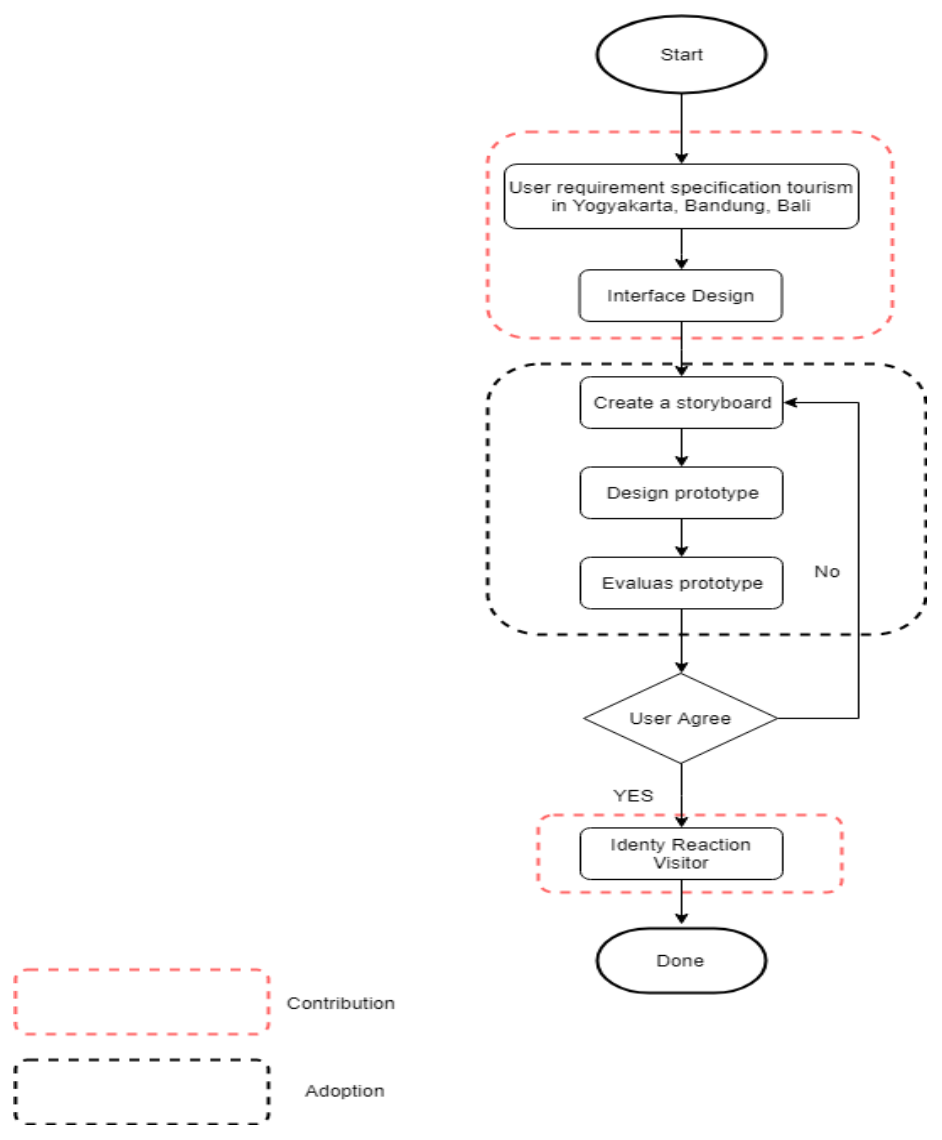

Fig. 1. Research Flow Diagram

The prototype design uses Android Studio tools are compatible with Android operating systems. Desian prototype consists of offline and online systems. Rewards are given to the online system because the data will be processed on the server.

The method proposed in this study is a user-centered design (UCD) that focuses on users or tourists. The needs analysis phase identifies the user needs for the mobile application that was created. The analysis process includes the design process that is aimed at the user in the process of designing interface applications required by users (Wardana et al., 2017), in the field of tourism. Thus, the UCD step begins with the identification of users and all stakeholders, as well as all related systems (Brunner et al., 2017). Data collection at this stage is by extracting information used in data collection for user needs, after which information is organized from data collected and explained in various forms or techniques, such as narratives, tables or diagrams. The results of the design can be sketches, simulations, and ways of prototypes used to provide information or effective communication to users (Brunner et al., 2017). The design evaluation phase is used to get feedback/responses whose results can improve 
the product and can be used to determine whether the design meets the user's expectations.

At the design evaluation stage, to get the application design done by the user, the questionnaire was adopted from previous studies (Gao et al., 2018), totalling ten questions that would be given to respondents. The survey is related to the initial application design created in this study. The results of the questionnaire will be used in evaluating and identifying reactions from users about the design of the proposed application. The initial design will be evaluated according to the user's wishes based on the results of the questionnaire. Questions related to the initial design of tourism application service guidelines are in table 1.

Table 1. Design of guide application service tourism questionnaire

\begin{tabular}{|c|l|c|c|c|c|c|}
\hline No & \multicolumn{1}{|c|}{ Question } & \multicolumn{4}{|c|}{ Opinion of Respondents } \\
\hline & & SA & \multicolumn{1}{|c|}{ A } & N & MD & DS \\
\hline 1 & It is useful & & & & & \\
\hline 2 & It meets my needs & & & & & \\
\hline 3 & It is easy to use & & & & & \\
\hline 4 & It is simple to use & & & & & \\
\hline 5 & I can use it without written instructions & & & & & \\
\hline 6 & I easily remember how to use it & & & & & \\
\hline 7 & It is easy to learn to use it & & & & & \\
\hline 8 & I am satisfied with it & & & & & \\
\hline 9 & It is fun to use & & & & & \\
\hline 10 & It is wonderful & & & & \\
\hline
\end{tabular}

Description: $\mathrm{SA}=$ Strongly Agree, $\mathrm{A}=$ Agree, $\mathrm{N}=$ Neutral, $\mathrm{MD}=$ Mostly Disagree, DS $=$ Disagree

Table 2 is a question that will be used in evaluating the initial design of tourism service guidelines. In the calculation using a liqueur scale. The value of each response given differs differently. Strongly agree worth 5 , agree 4 , neutral 3 , disagree value 2 and disagree worth 1 .

\section{Result}

Based on the results of observations made, the initial design of the prototype was made. The initial design of the prototype of the guide service tourism was made for the initial design resulting from the analysis of user needs and systems at the time of observation at heritage tourism sites. The initial design of the prototype as a whole can be seen in Figure 2. Based on the results of the comments made, the initial prototype design was made. 


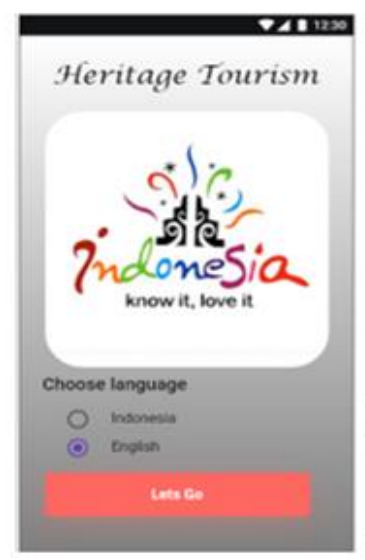

(a)

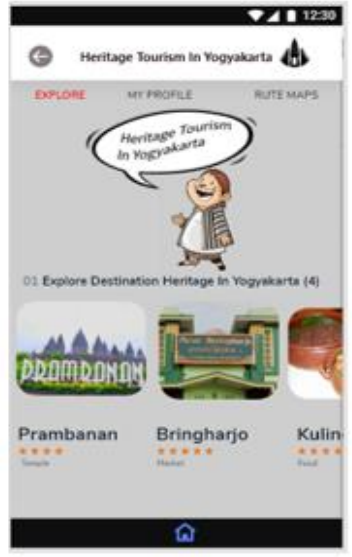

(d)

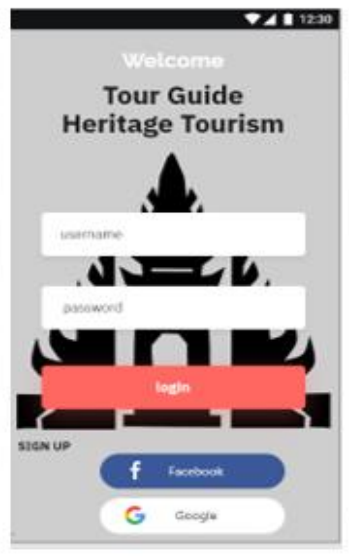

(b)

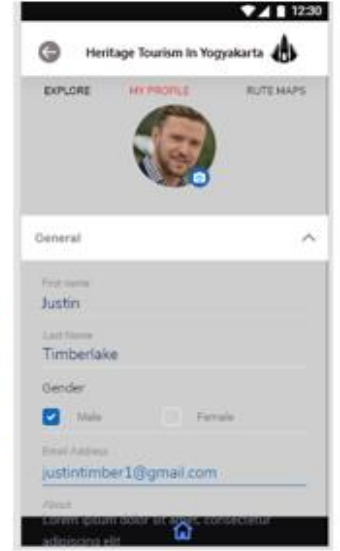

(e)

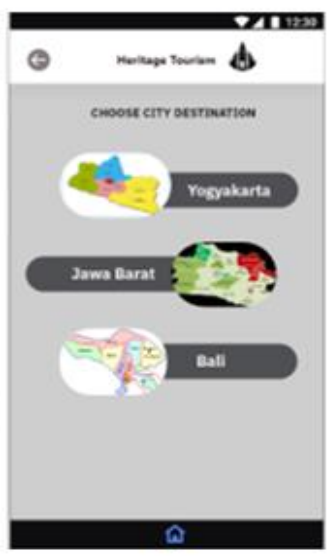

(c)

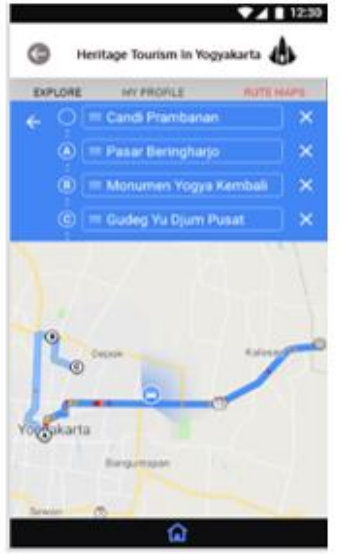

(f)

Fig. 2. Preliminary design of the prototype

Figure 2 is the initial design of the application interface. The interface design is made to make it easier for users to use the guide service tourism application, so a choice of languages is made, namely Indonesian and English when the form is opened as in Figure 2 (a). The design of the login page has several components that can help other users if the user is registered, then enter the user and password then login. If you have not registered, then click sign up to register, besides that, you can register using your Facebook account or Google account so that the registration process can be more comfortable for users. You are broadly speaking the design of the login page, as shown in Figure 2 (b).

The initial design of the interface is presented by making it easier for users to choose heritage tourism areas in Indonesia, namely Yogyakarta, West Java, and Bali, as shown in Figure 2 (c). Also, there are three main menus, namely Explore, My Profile, and 
Route. The explore menu is used to explain tourist attractions to be visited based on the tour package, as shown in Figure 2 (d). My profile menu is used to provide user profile information that contains various kinds of data from users of the application, as shown in Figure 2 (e). The route menu is used to explain the flow of travel from the starting point to the end of the tour, as shown in figure 2 (f).

The initial design of the prototype was evaluated by testing the prototype using the UCD approach. The initial design of the prototype was carried out by usability test perspective analysis using a questionnaire consisting of 10 questions related to the design of the tour guide service application. The distributed survey has received a response of 113 respondents. Characteristics of respondents in this study include gender, age, and education. The results of the analysis of the features of respondents can be seen in table 2.

Table 2. Frequency distribution based on respondent characteristics

\begin{tabular}{|c|c|c|}
\hline Respondents' background & Frequency (f) & Percentage \% \\
\hline \multicolumn{3}{|c|}{ Age } \\
\hline $16-20$ & 12 & $10.6 \%$ \\
\hline $21-25$ & 38 & $33.6 \%$ \\
\hline $26-30$ & 52 & $46.0 \%$ \\
\hline $31-35$ & 9 & $8.0 \%$ \\
\hline $36-40$ & 2 & $1.8 \%$ \\
\hline Male & Gender & $51.3 \%$ \\
\hline Female & 58 & $48,7 \%$ \\
\hline Senior High School & 55 & $26.5 \%$ \\
\hline Associate Degree & 30 & $14.2 \%$ \\
\hline Bachelor Degree & 28 & $54.0 \%$ \\
\hline Master Degree & 61 & $5.3 \%$ \\
\hline
\end{tabular}

Table 2 shows that there are more 26-30 years old as many as 52 respondents $(46.0 \%)$ then the characteristics of respondents based on gender are more male as many as 58 respondents $(51.3 \%)$ and the characteristics of respondents based on their most recent education many bachelor degrees are 61 respondents $(54.0 \%)$.

The results of prototype testing are used to evaluate the design of the prototype that is suitable for the user. Also, suggestions and opinions from users are used in assessing prototype designs. Overall design evaluation is based on prototype testing, as shown in Figure 3. 


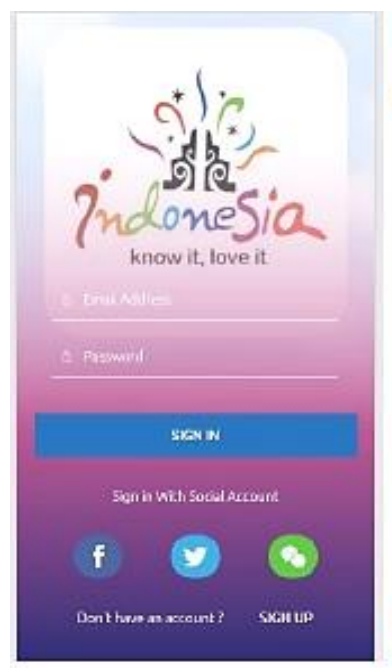

(a)

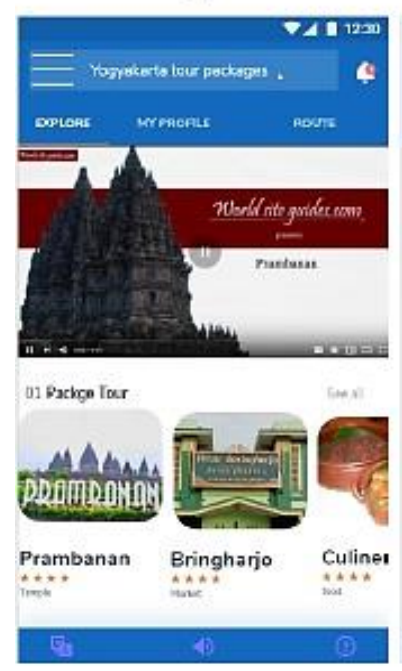

(d)

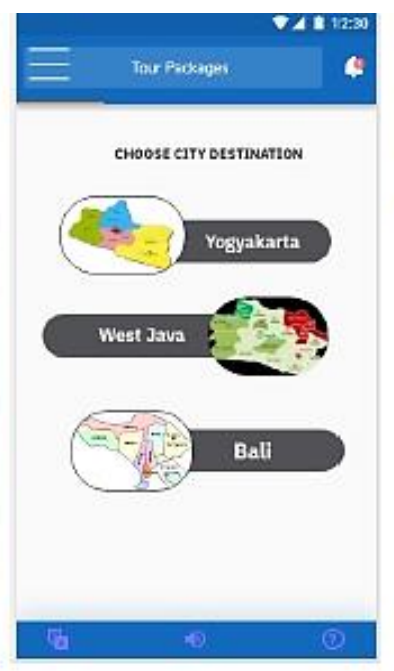

(b)

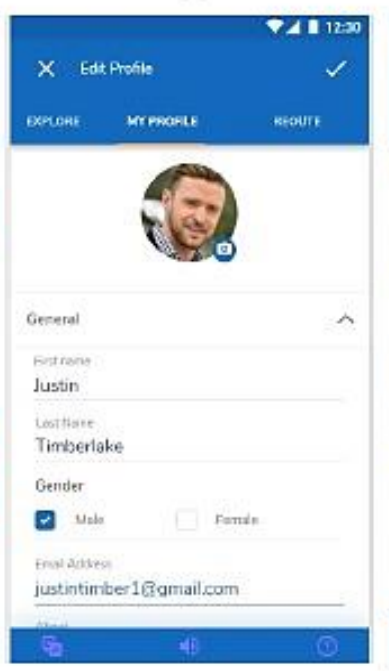

(e)

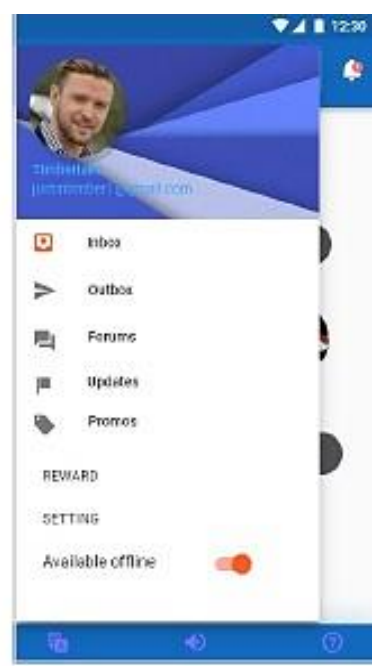

(c)

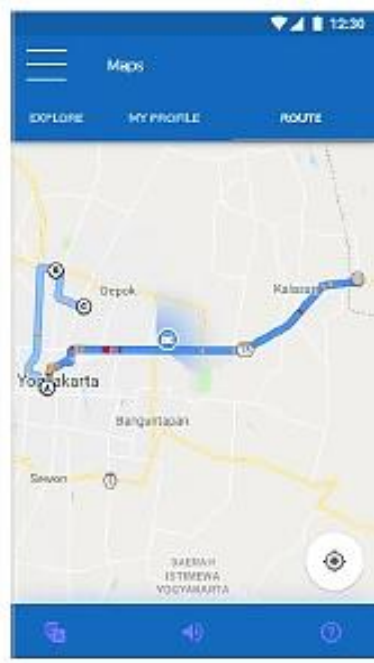

(f)

Fig. 3. Evaluation design from the user's perspective

Figure 3 is the result of an evaluation from the user's perspective, and evaluation is carried out based on the recommendations of the respondents. The first evaluation design is the background of the mobile application by changing it to be simpler so that it looks comfortable for the user. The second evaluation is a more vibrant color gradation design that users are not bored to see information on the application. The last evaluation is the addition of videos on the application that the application users not only read or know through the images available, can via video in providing information about heritage tourism that it is more interesting. 
In the application using a user-centered design is a specialized application created for tourists who want to do heritage tours. Analysis of the user's perspective on application design based on the results of the questionnaire can be seen in table 3 .

Table 3. The results of the user's perspective

\begin{tabular}{|c|l|c|c|c|c|}
\hline \multirow{2}{*}{ Question } & \multicolumn{1}{|c|}{ Variable } & \multicolumn{4}{c|}{ Information } \\
\cline { 3 - 5 } & & Mean & Stdev & $\begin{array}{c}\text { 95\% Confident } \\
\text { Interval }\end{array}$ & Percent \% \\
\hline Q1 & Usefulness & 4.04 & 0.69 & 3.92 to 4.17 & $81 \%$ \\
\hline Q2 & Usefulness & 3.92 & 0.76 & 3.78 to 4.06 & $78 \%$ \\
\hline Q3 & Ease of Use & 3.97 & 0.69 & 3.85 to 4.10 & $79 \%$ \\
\hline Q4 & Ease of Use & 3.97 & 0.69 & 3.85 to 4.10 & $79 \%$ \\
\hline Q5 & Ease of Use & 3.93 & 0.69 & 3.80 to 4.06 & $79 \%$ \\
\hline Q6 & Ease of Learning & 3.89 & 0.66 & 3.77 to 4.02 & $78 \%$ \\
\hline Q7 & Ease of Learning & 3.97 & 0.69 & 3.85 to 4.10 & $79 \%$ \\
\hline Q8 & Satisfaction & 3.58 & 0.91 & 3.40 to 3.75 & $72 \%$ \\
\hline Q9 & Satisfaction & 3.77 & 0.86 & 3.61 to 3.93 & $75 \%$ \\
\hline Q10 & Satisfaction & 3.65 & 0.91 & 3.48 to 3.81 & $73 \%$ \\
\hline Overall average percentage & & & & $77 \%$ \\
\hline
\end{tabular}

Table 3 shows the results of the calculation of each question questionnaire to get a percentage of each question.

$$
\text { Index formula } \%=\frac{\text { Total Score }}{Y \times 100}
$$

The total score is the score obtained from the respondents' answers. Y is the highest Likert score times the number of respondents. Then each statement can get a different percentage according to the answers given by respondents on a Likert scale. Then the entire proportion of the ten comments is calculated on average by $77 \%$. Next, look for present score intervals using the interval formula.

$$
\begin{gathered}
\text { Interval }=\frac{100}{\text { scala likert score }} \\
\text { Interval }=\frac{100}{5}=20
\end{gathered}
$$

Criteria for interpretation of scores based on intervals are as follows:

Range $0 \%-19.99 \%=$ Very (disagree / bad / very poor)

Range $20 \%-39.99 \%=$ Disagree $/$ Not good)

Range $40 \%-59.99 \%=$ Sufficient $/$ Neutral

Range $60 \%-79.99 \%=($ Agree $/$ Good $/$ Like $)$

Range $80 \%-100 \%=$ Very (agree / Good / Like)

The average amount with a yield of $77 \%$ is included in the Agree / Good / Like category which shows that the design of the application is in line with user expectations. 


\section{Contribution}

The contribution of this study is broadly outlined as follows:

1. Guide service tourism application using a user-centered design specifically for heritage tourism.

2. The methods of heritage tourism mobile applications are by utilising tourism providers and visitors.

3. Increase user knowledge about heritage tourism

The contribution in this research is to the method used, namely the UCD method, which has not been used in previous research in the field of heritage tourism on the application of heritage tourism services. in this study using the UCD method because UCD is a repeatable design approach that aims to develop an understanding of user needs, in this study are tourists. By using the UCD method can design applications by user expectations.

\section{Conclusion}

Heritage tourism is a recreational trip that has a historical heritage value in an area as its attraction. Heritage tourism development plays an essential role in promoting/introducing and preserving inheritance from the hinterland. Technology can be used in developing heritage tourism by delivering information and history of success to be more comfortable. This study proposes a mobile guide service application that is used to provide information and knowledge of heritage tourism in Indonesia. The approach used in this study is UCD. Then the prospective analysis was carried out using the questionnaire with ten questions distributed randomly. The distributed survey received responses from 113 respondents. The results were analysed and a total score of $77 \%$ was obtained which shows that this research was successful in designing Mobile Travel Guide Services for Heritage Tourism in Indonesia according to user needs. From the results of the distribution of questionnaires that have been done, obtained some input from the user is adding interactive videos and changing the background of the mobile application with attractive color gradations so that it looks comfortable to the user.

\section{$7 \quad$ References}

[1] Aguilar, S.J., Holman, C., Fishman, B.J., 2015. Game-Inspired Design: Empirical Evidence in Support of Gameful Learning Environments. Games Cult. https://doi.org/10.1177 $\underline{1555412015600305}$

[2] Alamäki, A., Dirin, A., 2014. Designing Mobile Guide Service for Small Tourism Companies Using User Centered Design Principle. Proc. Int. Conf. Comput. Sci. Comput. Eng. Soc. Media, Thessaloniki, Greece, 2014 47-58.

[3] Asmelash, A.G., Kumar, S., 2019. The structural relationship between tourist satisfaction and sustainable heritage tourism development in Tigrai, Ethiopia. Heliyon 5, e01335. https://doi.org/10.1016/j.heliyon.2019.e01335 
[4] Brox, E., Konstantinidis, S.T., Evertsen, G., 2017. User-Centered Design of Serious Games for Older Adults Following 3 Years of Experience With Exergames for Seniors: A Study Design. JMIR Serious Games 5, e2. https://doi.org/10.2196/games.6254

[5] Brunner, J., Chuang, E., Goldzweig, C., Cain, C.L., Sugar, C., Yano, E.M., 2017. Usercentered design to improve clinical decision support in primary care. Int. J. Med. Inform. 104, 56-64. https://doi.org/10.1016/j.ijmedinf.2017.05.004

[6] Chiao, H.-M., Chen, Y.-L., Huang, W.-H., 2018. Examining the usability of an online virtual tour-guiding platform for cultural tourism education. J. Hosp. Leis. Sport Tour. Educ. 23, 29-38. https://doi.org/10.1016/j.jhlste.2018.05.002

[7] Constantinou, V., Loizides, F., Ioannou, A., 2016. Digital Heritage. Progress in Cultural Heritage: Documentation, Preservation, and Protection, Lecture Notes in Computer Science. Springer International Publishing, Cham. https://doi.org/10.1007/978-3-319-48496-9

[8] Dickinson, J.E., Filimonau, V., Cherrett, T., Davies, N., Hibbert, J.F., Norgate, S., Speed, C., 2018. Lift-share using mobile apps in tourism: The role of trust, sense of community and existing lift-share practices. Transp. Res. Part D Transp. Environ. 61, 397-405. https://doi.org/10.1016/j.trd.2017.11.004

[9] Dirin, A., Laine, T.., Alamäki, A., 2018. Managing Emotional Requirements in a ContextAware Mobile Application for Tourists. Int. J. Interact. Mob. Technol. 12, 177. https://doi.org/10.3991/ijim.v12i2.7933

[10] Esteves, M., Pereira, A., 2015. Y.S.Y.D. - You Stay You Demand: User-centered design approach for mobile hospitality application, in: 2015 International Conference on Interactive Mobile Communication Technologies and Learning (IMCL). IEEE, pp. 318-322. https://doi.org/10.1109/IMCTL.2015.7359611

[11] Gao, M., Kortum, P., Oswald, F., 2018. Psychometric Evaluation of the USE (Usefulness, Satisfaction, and Ease of use) Questionnaire for Reliability and Validity. Proc. Hum. Factors Ergon. Soc. Annu. Meet. 62, 1414-1418. https://doi.org/10.1177/1541931218621322

[12] Gretzel, U., Sigala, M., Xiang, Z., Koo, C., 2015. Smart tourism: foundations and developments. Electron. Mark. 25, 179-188. https://doi.org/10.1007/s12525-015-0196-8

[13] Gulbahar, M.O., Yildirim, F., 2015. Marketing Efforts Related to Social Media Channels and Mobile Application Usage in Tourism: Case Study in Istanbul. Procedia - Soc. Behav. Sci. 195, 453-462. https://doi.org/10.1016/j.sbspro.2015.06.489

[14] Hamdi, M., Hamtini, T.M., 2016. Designing an Effective e-Content Development Framework for the Enhancement of Learning Programming. Int. J. Emerg. Technol. Learn. 11, 131. https://doi.org/10.3991/ijet.v11i04.5574

[15] Ismaeel, D.A., Al-Abdullatif, A.M., 2016. The Impact of an Interactive Virtual Museum on Students' Attitudes Toward Cultural Heritage Education in the Region of Al Hassa, Saudi Arabia. Int. J. Emerg. Technol. Learn. 11, 32. https://doi.org/10.3991/ijet.v11i04.5300

[16] Jeon, M.M., Kang, M., Desmarais, E., 2016. Residents' Perceived Quality Of Life in a Cultural-Heritage Tourism Destination. Appl. Res. Qual. Life 11, 105-123. https://doi.org/10.1007/s11482-014-9357-8

[17] Jung, T.H., Lee, H., Chung, N., tom Dieck, M.C., 2018. Cross-cultural differences in adopting mobile augmented reality at cultural heritage tourism sites. Int. J. Contemp. Hosp. Manag. 30, 1621-1645. https://doi.org/10.1108/IJCHM-02-2017-0084

[18] Kosmas, P., Galanakis, G., Constantinou, V., Drossis, G., Christofi, M., Klironomos, I., Zaphiris, P., Antona, M., Stephanidis, C., 2019. Enhancing accessibility in cultural heritage environments: considerations for social computing. Univers. Access Inf. Soc. https://doi.org/10.1007/s10209-019-00651-4

[19] Marimin, 2016. Cultural heritage as a tourist destination: A focus on Surakarta Kasunanan Palace in Indonesia. J. Environ. Manag. Tour. 7, 723-732. 
[20] McGookin, D., Tahiroğlu, K., Vaittinen, T., Kytö, M., Monastero, B., Carlos Vasquez, J., 2019. Investigating tangential access for location-based digital cultural heritage applications. Int. J. Hum. Comput. Stud. 122, 196-210. https://doi.org/10.1016/j.ijhcs.2018.09.009

[21] Muljono, M., Saraswati, G.W., Winarsih, N.A.S., Rokhman, N., Supriyanto, C., Pujiono, P., 2019. Developing BacaBicara: An Indonesian Lipreading System as an Independent Communication Learning for the Deaf and Hard-of-Hearing. Int. J. Emerg. Technol. Learn. 14, 44. https://doi.org/10.3991/ijet.v14i04.9578

[22] Neidhardt, J., Werthner, H., 2018. IT and tourism: still a hot topic, but do not forget IT. Inf. Technol. Tour. 20, 1-7. https://doi.org/10.1007/s40558-018-0115-x

[23] Risald, R., Suyoto, S., Santoso, A.J., 2018. Mobile Application Design Emergency Medical Call for the Deaf using UCD Method. Int. J. Interact. Mob. Technol. 12, 168. https://doi.org/10.3991/ijim.v12i3.8754

[24] Roth, R., Ross, K., MacEachren, A., 2015. User-Centered Design for Interactive Maps: A Case Study in Crime Analysis. ISPRS Int. J. Geo-Information 4, 262-301. https://doi.org/10.3390/iigi4010262

[25] Schnall, R., Rojas, M., Bakken, S., Brown, W., Carballo-Dieguez, A., Carry, M., Gelaude, D., Mosley, J.P., Travers, J., 2016. A user-centered model for designing consumer mobile health (mHealth) applications (apps). J. Biomed. Inform. 60, 243-251. https://doi.org/10.1016/j.jbi.2016.02.002

[26] Song, H., Qiu, R.T.R., Park, J., 2019. A review of research on tourism demand forecasting: Launching the Annals of Tourism Research Curated Collection on tourism demand forecasting. Ann. Tour. Res. 75, 338-362. https://doi.org/10.1016/j.annals.2018.12.001

[27] Statistik, B.P., 2018. Perkembangan Pariwisata dan Transportasi Nasional Juni 2018.

[28] Su, R., Bramwell, B., Whalley, P.A., 2018. Cultural political economy and urban heritage tourism. Ann. Tour. Res. 68, 30-40. https://doi.org/10.1016/j.annals.2017.11.004

[29] Suphachaimongkol, C., Ratanatamskul, C., Silapacharanan, S., Utiswannakul, P., 2019. Development of Mobile Application for Sustainable Creative Tourism Assessment using Confirmatory Factor Analysis Approach. Int. J. Interact. Mob. Technol. 13, 27. https://doi.org/10.3991/ijim.v13i06.10500

[30] Vainstein, N., Kuflik, T., Lanir, J., 2016. Towards Using Mobile, Head-Worn Displays in Cultural Heritage, in: Proceedings of the 21st International Conference on Intelligent User Interfaces - IUI '16. ACM Press, New York, New York, USA, pp. 327-331. https://doi.org/10.1145/2856767.2856802

[31] Wardana, L.A., . S., . P., 2017. Design Mobile Application of Marriage Counseling on the Catholic Church with UCD and Wireframe Method. Int. J. u- e- Serv. Sci. Technol. 10, 153162. https://doi.org/10.14257/ijunesst.2017.10.1.13

[32] Xu, F., Buhalis, D., Weber, J., 2017. Serious games and the gamification of tourism. Tour. Manag. 60, 244-256. https://doi.org/10.1016/j.tourman.2016.11.020

\section{Authors}

Erni Widarti is a Master of Informatics Engineering Student at Universitas Atma Jaya Yogyakarta, Yogyakarta, Indonesia. She is a scholar of the Universitas Boyolali. Her research interests are the mobile app, web programming, and user interface design.

Dadang Eman is a Master of Informatics Engineering Student at Universitas Atma Jaya Yogyakarta, Yogyakarta, Indonesia. He is a scholar of the Universitas Respati 
Yogyakarta. His research interests are the mobile app, web programming, and user interface design

Suyoto is Professor in the Department of Informatics Engineering at Universitas Atma Jaya Yogyakarta, Yogyakarta, Indonesia. He has more than seventeen years of teaching experience. He received his Ph.D. in 2000 from the National University of Malaysia, Malaysia. His research interests are multimedia, computer graphics, visualisation, mobile application, and artificial intelligence.

Article submitted 2019-07-16. Resubmitted 2019-09-05. Final acceptance 2020-01-22. Final version published as submitted by the authors. 